\title{
Research on the Development Status and Countermeasures of Chinese Youth Amateur Basketball Training
}

\author{
Zuming Jia \\ Zhengzhou Foreign Language School, China
}

\begin{abstract}
In order to study the significance of the development of the youth basketball training industry in China and find the main factors that affect youth basketball training industry in China, this paper adopts literature method, to study the development situation of basketball training market in China and analyze the significance and relevant factors of carrying out youth basketball training. Through the study, we found that: site location, site management, the pressure of examination middle school students face, the qualification of coaches and training institutions are the main influencing factors of youth basketball training. Therefore, for the Chinese youth basketball training market to get a good development, the next steps that should be implemented include: the government should allocate and integrate resources reasonably; The education department should change the traditional teaching concept; The supervisory department should strengthen the supervisory mechanism of basketball training institutions; Basketball coaches should improve their comprehensive level.
\end{abstract}

Keywords: Basketball training; teenager; Mass sports; the sports industry.

\section{中国青少年业余篮球培训发展现状与对策研究}

\section{贾祖铭}

\section{郑州外国语新枫杨学校 河南 中国}

摘 要: 为了研究中国现阶段青少年篮球培训产业的发展现状、意义以及发现影响中国青少年 篮球培训产业的主要因素, 本文采用文献资料法, 对中国当前篮球培训市场的发展形势进行研 究, 分析开展青少年篮球培训的意义和相关因素。经过研究我们发现: 场地位置及场地管理, 中 学生面临的应试压力, 教练员以及培训机构资质是青少年篮球培训的主要影响因素。因此, 为 了中国青少年篮球培训市场获得良好发展, 下一步应当实施的步骤包括:政府应当合理分配及 整合资源; 教育部门应当转变传统教学观念; 监管部门完善篮球培训机构的监管机制; 篮球教 练员应当提升自身综合水平。

关键词：篮球培训;青少年;群众体育;体育产业。

\section{1. 引言}

在中国社会主义市场经济体制改革的背景下, 公民的生活方式发生了巨大的改变, 进而影响着 人们的消费观念。随着体育运动的普及和发展, 体育运动的培训正在吸引着人们的关注。因此, 在这种情况下, 国家也出台了相关政策进行推动。例如, 国务院于 2014 年10月出台的《关于加快 发展体育产业促进体育消费若干意见》, 为中国的体育发展事业提供了明确的目标与方向。《意 见》中指出:体育产业总规模超过 5 万亿元, 成为推动经济社会持续发展的重要力量 [1]。在近些 年来形成的经济型常态下, 中国体育产业有着空前的发展机遇和挑战。而在中国有着巨大体育 群众基础的背景下, 诸多体育项目, 如羽毛球, 乒乓球, 篮球等深深吸引人们的关注。在篮球足 球等球类运动中, 因为足球等运动由于对场地面积及质量有着高要求, 因此他们更多的是以校 园运动的方式存在。与此不同, 篮球是中国普及率非常高的体育项目之一, 在篮球逐渐普遍化 
并且篮球场数量逐渐增多的前提下, 篮球产业的发展正在飞速发展 [2]。但是, 各个地区篮球培 训机构在蓬勃发展的同时, 也在发展中出现了一系列的问题。比如, 众多的篮球培训机构过于 关注经济利益, 而对提升青少年篮球水平以及身体素质有所忽视, 使得青少年篮球水平没有显 著提升; 规范化篮球培训场地不足; 培训人员并非专业化教练员, 而是一些篮球爱好者; 没有完 善的篮球培训对策与方案, 在篮球产业发展的同时, 由于社会发展及篮球运动爱好者数量的庞 大, 篮球运动逐渐成为人们锻炼身体和生活娱乐的重要组成部分, 参加篮球运动的人数与日俱 增。据有关数据统计, 在参与篮球运动的群众中, 青少年占到 $36 \%[3]$ 。该产业在发展中出现了 一系列的问题, 比如: 各个地区的篮球培训机构数目众多, 但是由于篮球培训机构的突发激增, 导致了众多机构的最终目的并不是以提升青少年篮球能力及身体素质为主要目的。本文将针 对以上提出的问题进行研究分析, 以便对相关主管部门的政策制定及体育培训相关机构的发 展有所裨益。

\section{2. 现阶段中国青少年篮球培训市场的基本状况}

\section{1. 社会经济发展与国家政策推动}

近年来, 伴随着社会的飞速发展, 人们的生活环境有了质的提升, 进而人们的健康观念有了改 变, 人们的关注点由原先的衣食住行转变为对身体健康等方面的关注, 因此推动了中国青少年 体育运动市场的发展。年轻人是篮球后备人才的主力军, 业余篮球训练拥有更多的青少年篮球 爱好者, 有巨大的发展前景 [4]。在国家对青少年体育运动十分重视的背景下, 有关青少年体育 运动的诸多政策也相应出台, 其中中国政府在 46 号文中提出 “到 2025 年, 人均体育场地面积达 到 2 平方米, 经常参加体育锻炼的人数达到 5 亿”。首先, 该政策的提出大大促进了国内政府以 及有关体育运动机构的发展, 在此种发展前景下, 有许多其他的行业也转行进军体育培训产业 。而在众多体育项目中, 足球、篮球日最为受到广大人民群众的喜爱。在各中小学体育教育的引 导下, 篮球运动成为很多青少年最为喜爱的体育运动项目之一 [5]。2018年, 青少年体育组织类 型不断丰富, 规模不断扩大, 布局更加均衡, 服务与发展能力明显加强。国家示范性青少年体育 俱乐部达到 300 家, 各级青少年体育俱乐部达到 12000 家, 每 2 万名青少年拥有 1 家青少年体育俱 乐部”, 这使得青少年篮球培训引起了国家及社会层面的更多关注 [6]。此外, 在中国政府逐渐 重视青少年身体健康并提出了 “到2020年, 青少年体育活动更加广泛, 青少年训练基础更加坚 实, 青少年基本公共体育服务城乡、区域更加协调”。这一政策的提出, 更加促进篮球产业成为 中国当前一大热门体育运动, 使得中国青少年篮球体育培训市场迎来了新的春天。

\section{2. 培训机构资金来源与机构组成}

国家非常重视篮球培训产业的发展, 因此, 当前中国篮球培训市场较为丰富, 各个相关部门、社 会机构相继开展篮球培训营。普遍的开发模式主要包括政府模式、民间模式、政府民间模式三 种 $[7]$ 。其中, 部分是由政府提供资金组办, 还有部分是由公司组建, 另外还有政府与公司联合 承办。在以政治社会, 公司与合作的三种运行组建方式中, 以政府和社会名义运营发展的篮球 培训所虽然推广性较强, 但是由于配置效率低使得其占比例较少, 更多的是倾向于各公司自行 承办的资源配置效率高的篮球培训机构。政府所执导运营的篮球培训机构的培训方式较为传 统, 而由公司组办的培训机构相对而言更符合当前社会发展形势, 也因此发展得更加迅速, 且 
在篮球培训市场中占有绝大部分。在篮球培训机构组成中, 部分的培训机构有专业的训练场地 与专业的辅导教练, 并且还有明确的培训规划以及收费标准, 这些机构通常会有固定的训练时 间并且具有持续性。而另外一种篮球培训机构就相对较为标准化,这些机构的场地大多集中于 一些校园内部的篮球场地, 因此这些篮球培训机构的训练时间较为局限, 仅可以在假期和周末 进行培训。并且由于场地环境因素, 训练时间会受到天气因素影响, 从而降低训练质量。

\section{3. 篮球培训项目的开展优势}

根据第六次人口普查公报, 中国共有 4.65 亿青少年, 占全国总人口数量的 $36.25 \%$ [8]。中国青少 年体质健康连续26年下滑, 而且这个趋势尚未停止。中国青少年体质健康问题逐步受到党中央 国务院的重视, 国家明确制定了《加强青少年体育, 增强青少年体质健康的指导意见》。在 “健 康中国 2030 ” 战略出台后, 人们对于健康的意识提高, 并且开始重视体育运动。篮球成为了当 前最受欢迎的体育运动之一, 篮球运动可以提高青少年身体素质, 在进行篮球运动的过程中, 青少年可以在合作中学习到团队精神, 在竞技中得到身体锻炼与意志磨练。并且, 当前国家对 篮球运动的重视逐渐提升, 中国篮球联盟 CBA 渐渐发展壮大, 国家对于高水平篮球运动员的需 求迫在眉睫, 因此, 篮球培训产业在提升国民身体素质的同时, 还肩负着为国家篮球事业发展 作出贡献的责任。此外, 篮球运动除了有着增强身体素质等外在优势, 还可以进一步促进篮球 学员的内在优势培养。比如在球场上, 面对不同的竞技局面, 球员需要随机应变来应对赛场, 因 此, 球员的随机应变能力可以得到提升。篮球运动对于球员的心理素质也有极大的提升, 由于 在比赛中球员会受到各种因素的影响, 球队比分也时刻会有所波动, 所以球赛具有不确定性, 如若球员们的心理素质不够过硬, 他们就可能会在比赛中, 因为失误或者其他原因而导致的比 分落后, 使得篮球水平不能完全发挥出来。但是如果篮球球员能够接受专业的训练, 此类情况 将会大大避免, 球员可以在比赛中自我调节, 从而发挥出更加稳定水平。中国当前应当十分重 视当代青少年的身体素质, 因为青少年是祖国的未来, 他们的身心健康, 政府应该给予应有的 重视, 在培训机构日益增多的时候, 政府要对其严加把关, 使青少年的篮球培训有一个正确且 健康的发展 $[9]$ 。

\section{4. 篮球教练员的总体水平}

篮球教练, 是影响篮球培训机构发展的重要因素。篮球教练的素质水平, 直接关系着篮球培训 机构的未来发展。因此, 高水平的篮球教练员对中国青少年业余篮球发展起着至关重要的作用 。而当前由于中国刚刚发展起篮球事业, 对于篮球行业的重视还不够全面, 在国内各大高校中 篮球专业也是十分稀缺, 再加上当前社会中对篮球教练员所提供的工作前景还不是十分理想, 这就会使得许多对篮球事业感兴趣的人迫于就业和生活压力而选择了其他工作。面对当前需 求量激增的篮球培训市场, 社会中对于专业训练师的需求突然增多, 这使得部分篮球培训机构 请不到高端训练师, 而导致篮球水平无法大幅度提升。只有部分篮球培训机构斥巨资请国外的 专业训练师进行培训。 


\section{3. 中国青少年业余篮球培训的影响因素}

\section{1. 场地位置及场地管理}

伴随着国家政策的大力支持, 中国青少年篮球业余培训也吸引了来自各个方面的投资, 因此许 多培训机构也相应而生, 但是由于各个机构缺乏相关法律法规的约束, 又加之政府管理部门的 监管力度不够, 导致青少年篮球培训机构难以合法化, 而这一状况在篮球场地的运用方面体现 的最为明显。根据数据统计, 约 $81 \%$ 的培训机构认为场地是制约篮球培训的主要因素, 有时候甚 至是决定性因素 [10]。因此, 建设并使用正规的篮球场地是一个篮球培训机构的首要任务。但 是, 由于当前社会对于篮球的重视程度处于初步阶段, 正规篮球场的数量也是十分稀缺的, 并 且, 目前为数不多的正规篮球场并不对外开放。此外, 由于各个篮球培训机构的资金不足, 无法 自行建设正规篮球场并为训练员提供良好的训练环境, 这使得中国青少年篮球培训发展受阻。 在这种情况下, 如果国家在就篮球训练场地一方面有更多投入, 比如调控篮球场地的租金、优 化篮球培训设备, 那么场地问题将会得到更快的解决。

\section{2. 中国学生面临的应试压力}

中国当前正在飞速发展, 这也归功于中国教育体系的完善, 在这样的情况下, “知识改变命运” 的这一传统观念也中国家长的脑海里扎起了根, 也正是在这一原因下, 中国青少年篮球培训也 受到了重大影响。据数据统计: 在四川省, 培训学员中 $43 \%$ 的人打算放弃篮球培训, 其中因为学 业压力较大想放弃的有 $60 \%$, 包括很多长期进行篮球培训的学生, 中断训练的原因也正在于此 $[10]$ 。因此, 许多的接受篮球培训的学生或者家长只是想让学生得到适量的体育训练, 从而强 健体魄, 并非是要实实切切地提高青少年的篮球水平。而且, 家长们也担心篮球训练会导致学 生文化成绩受到影响, 所以当篮球培训与学习发生冲突时, 他们还是会选择放弃篮球培训。由 于当前学生面临各种学业压力, 学生为了取得优异的成绩, 他们把大量的时间使用在学习上, 使得学生们仅仅留下十分稀少的空闲时间去进行自己喜欢的活动, 而能够分配到篮球培训上 的时间是少之又少的。

\section{3. 教练员以及培训机构资质}

随着国家大力推进和发展篮球运动, 青少年的篮球培训这个项目也吸引了很多的人来投资开 班, 机构越开越多, 但因为相关法律法规的不完善, 政府机关的监管力度不够, 导致很多青少年 篮球培训机构难以合法化 [11]。而目前中国市场的篮球培训机构类型主要分为三种:政府承办 篮球培训机构, 各公司自行建立的篮球培训机构以及政府和公司共有承办的篮球培训机构。政 府承办的篮球培训机构, 由国家亲自开展, 因此标准较为严格, 教练员也是通过层层选拔而挑 选出来的专业教练, 个体承办的篮球培训机构数量较少, 只占中国篮球培训市场的很小一部分, 而占篮球培训市场的主要数量的还是各个公司自行运营的培训机构。然而, 在这些机构中, 由 部分机构管理较于松懈, 对于教练员的篮选就没有那么的严格, 因此, 篮球一级或二级运动员、 参加过大型比赛的运动员、体育专业的大学生就可以充当教练员的职位, 另外, 还有一些篮球 爱好者通过给熟人的孩子上篮球培训课, 并且根据上课的培训方式而受到学生和家长的喜爱, 进而形成了篮球培训班, 使得这些培训班逐渐发展起来, 可是这些教练员并没有受到过专业训 练与培训, 这就导致教练员的资质受到质疑, 进而对于他们的篮球培训水平没有确定了解。并 且在对总体教练员的文化教育程度的调查上来看, 篮球教练员的学历普遍偏低 [12]。在这样的 
情况下, 不完善的培训机构管理会影响到招生过程中的种种问题, 非专业的教练员也会使学员 的培训质量受到影响。

\section{4. 青少年篮球培训的对策与建议}

\section{1. 政府应当合理分配与整合资源}

由于当前青少年篮球培训市场发展处于初步阶段, 在篮球培训的各个方面有待继续加强, 国家 和政府需要实施相应政策进而使得篮球培训的场地问题得到解决。当前中国一线城市有这样 一个发展趋势: 该城市将要建立指定的篮球正规场馆, 并且可以保证该市居民可以在一小时内 到达场馆, 此政策也可以将来在全国范围内推广起来, 为全国篮球爱好者提供便利条件。各个 机构应当在政府政策的支持下不断完善场地问题, 国家或者政府可以为篮球培训机构降低篮 球场地的租金问题. 这样就可以解决当前市场上各个培训机构篮球场地稀缺的问题。

\section{2. 教育部门应当转变传统教育观念}

随着社会的发展, 近年来人们对于青少年的体质问题也愈加关注。据数据统计, 近二十年以来, 中国青少年的体质水平逐渐下降, 由体检数据显示, 当前越来越多的青少年体检报告不达标。 因此, 中国政府以及教育部门为了改变这种令人担忧的状况, 增强学生身体素质进而提高学生 的学习成绩, 特此为学生的升学考试中加入体育考试, 由于体育达标测试占取不少分值, 为了 取得好成绩, 学生必须全面发展, 硬性的体育达标检测可以促使学生以及家长对学生的体育方 面引起重视, 学生家长也逐渐重视起来。于是家长们不仅要求学生学习和艺术能力, 他们也让 学生开始参加一些体育训练, 并且, 篮球作为中国高校体育教学项目中极具重要的项目之一, 它不仅有利于促进学生身心健康发展, 还有利于提高学生 的社会适应能力 [13]。对于当前体 育消费的主力军一大学生, 大学生体育素养培养思维革新, 有助于大学生更好融入 现代化体 育教育环境 [14]。因此, 在社会和政府的推进下, 中国青少年的身体素质将会有提升的趋势, 进 而为中国发展青少年篮球事业打下坚实的基础。

\section{3. 篮球培训机构应当完善监管机制}

为了使青少年的篮球水平得到显著提升, 为中国篮球队输送优质的篮球队员, 对于当今教练员 的资质问题, 中国政府以及各个青少年篮球培训机构应当十分重视。为改善教练员水平参差不 齐的状况, 政府相关机构应和培训机构建立严格的教练员招收政策, 对社会上各类篮球教练员 的招聘严格把关, 以防对于篮球学员造成负面影响。此外, 为了更高效地招收优质篮球教练员, 大学内的篮球专业学生应当有更严格的培训, 并且制定一系列的教育体系, 社会应当为想要以 篮球培训作为自身事业的篮球爱好者提供专业执证的考试平台, 并对教练员资格证进行严格 的考核机制。因此, 篮球培训机构在招收教练员时就会有评判标准, 进而可以提升教练员的专 业水平。

\section{4. 篮球教练员应当提升综合水平}

近年来, 随着经济社会的迅猛发展, 人们对服务性 消费需求大幅增加, 体育培训市场的地位和 作用越来越不可小觑 $[10]$ 。并且, 近些年来在一些类似 NBA 等大型篮球产业市场以及大众媒体 的推动下, 篮球已经成为当前青少年体育运动中不可缺少的一个项目。随着篮球文化的广泛传 
播和渗透, 现阶段, 篮球培训产业被视为朝阳产业, 大有发展的潜力 [15]。因此, 为了更好地为 青少年及大众篮球爱好者提供便利与优质培训, 中国政府以及各个机构应当相互配合, 促进篮 球产业的发展，也可以制定一系列相关的篮球培训章程用于规范篮球培训。各大篮球培训机构 也应当相互沟通培训学习, 相互取长补短, 培养出具有中国特色的篮球文化, 为中国的篮球事 业营造更好的未来。

\section{5. 结语}

伴随着中国体育产业市场的快速发展, 篮球市场也有着前所未有的良好发展机遇, 持续增多的 青少年篮球培训机构为青少年提供了提高篮球技术水平的条件。在市场的管理下,正规篮球场 的数量不断增多, 教练员质量也在不断优化。高校也在社会的推动下对篮球培训注入更多关注, 高校的重视、加强校企合作是提升中国篮球运动水平的重要途径, 也是培养与提 升学生综合 素养的重要举措。基于这样的发展趋势, 中国青少年的身体素质将会不断加强, 篮球水平不断 提升, 将来为中国的篮球事业作出贡献。

\section{References}

[1]. opinions of the State Council on accelerating the development of sports industry and promoting sports consumption [EB / OL]. Http:/www.gov.cn/zhengce/content/2019-9/20/content.Htm.

[2]. Wang Zhenzhong. Research on the current situation of youth amateur basketball training in Xianning City [J]. Chinese and foreign entrepreneurs, 2018 (26): 181-182.9.

[3]. Li Jiangtao, Hu Xingli. Analysis of current situation and promotion strategy of youth basketball training market in Sanya [J]. Anhui Sports Science and technology, 2017,38 (06): 22-24.

[4]. song Haikuan, He Fang. Research on development strategy of youth basketball training market in Yuhu District, Xiangtan City [J]. Contemporary sports technology, 2019,9 (05): 196-197 + 199.

[5]. Huang Zhihui. Research on motivation and purpose of youth participating in basketball training class in Xiamen [J]. Contemporary sports science and technology, 2019,9 (21): $207+209$.

[6]. notice of the General Administration of sport on printing and distributing the youth sports activity promotion plan [EB / OL]. Http://www.sport.gov.cn/n321/n372/c844024/content.html.

[7]. Ye Huiyin. Research on the development status and Countermeasures of youth basketball training market in Xiamen [J]. Contemporary sports technology, 2018,8 (13): 235-236.

[8]. Guo Zhiqiang. Research on youth basketball training [J]. Martial arts research, 2018,3 (04): 148$151+154$.

[9]. Liao Liqin. A study on the strategy of youth basketball training in Shanghai [J]. Chinese and foreign entrepreneurs, 2018 (13): 215.

[10]. Tian Hong, Zhou Yang. The current situation and influencing factors of basketball training market in Sichuan Province [J]. Journal of Chengdu Institute of physical education, 2014,40 (08): 46-49.

[11]. Zeng Zhi. Analysis of the current situation and promotion strategies of Loudi youth basketball training [J]. Modern economic information, 2018 (11): $457+461$. 
[12]. Yang Yaohua. Investigation and Research on the current situation of amateur basketball training of urban youth in Henan Province [J]. Sports culture guide, 2010 (07): 19-23.

[13]. Lin Yue. Analysis of relevant measures to improve the effect of basketball training in Colleges and universities [J]. Xue weekly, 2019 (21): 7.

[14]. Li Chuandong. Cultivation of College Students' sports scientific literacy and Research on lifelong sports [J]. Journal of Jiamusi vocational college, 2019 (06): $254+264$.

[15]. Chen Xin. Basketball culture and basketball market [D]. Suzhou: Suzhou University, 2007.155-162. 